\title{
Ureteric Stricture with Analgesic Nephropathy
}

\author{
GRAHAM A. MACGREGOR， N. F. JONES， M. A. BARRACLOUGH， A. J. WING， W. I. CRANSTON
}

British Medical fournal, 1973, 2, 271-272

\section{Summary}

Three patients with analgesic nephropathy are reported who, in addition to the accepted features of this syndrome, had dilatation of one or both upper urinary tracts due to ureteric or periureteric fibrosis without intraluminal obstruction. We attribute this lesion to analgesic abuse and suggest that any patient with unexplained ureteric fibrosis should be questioned about analgesic consumption. This association also suggests a possible role for analgesic abuse in the pathogenesis of retroperitoneal fibrosis.

\section{Introduction}

Since its original description by Spühler and Zollinger (1953), analgesic nephropathy has become well recognized as a clinical entity, and is encountered with increasing frequency. We report on three patients with analgesic nephropathy in whom the disease was complicated by the occurrence of ureteric fibrosis or stricture or both.

\section{Case 1}

A 48-year-old male journalist presented in November 1969 with a three-week history of episodic left loin pain, rigors, dysuria, and frequency. There was no history of previous illness or renal disease, but over the last two years he had taken up to 25 codeine compound tablets daily (codeine phosphate $8 \mathrm{mg}$, acetylsalicylic acid $250 \mathrm{mg}$, phenacetin $250 \mathrm{mg}$ ) for headaches.

He was anaemic and had a temperature of $101^{\circ} \mathrm{F}\left(38.3^{\circ} \mathrm{C}\right)$. The blood pressure was $170 / 90 \mathrm{~mm} \mathrm{Hg}$. Abnormalities on investigation included: $\mathrm{Hb} 8.6 \mathrm{~g} / 100 \mathrm{ml}$, E.S.R. $85 \mathrm{~mm}$ in the first hour, serum iron $25 \mu \mathrm{g} / 100 \mathrm{ml}$, unsaturated iron binding capacity $320 \mu \mathrm{g} / 100 \mathrm{ml}$, blood urea $44 \mathrm{mg} / 100 \mathrm{ml}$, plasma creatinine $1.4 \mathrm{mg} / 100 \mathrm{ml}$. The urine contained red and white cells and a trace of protein, and on culture grew Escherichia coli. Hippuran renogram showed impaired function and delayed excretion by the left kidney. Intravenous pyelogram (I.V.P.) showed delayed excretion on the left side with moderate hydronephrosis and dilatation of the pelvicaliceal system on this side. The upper one-third of the left ureter was dilated, but below this for a distance of $7 \mathrm{~cm}$ between the fourth lumbar vertebra and the pelvic brim it was not seen. Below this the calibre was normal. A left ureterogram showed the ureter to be tortuous and irregular in calibre in its middle portion but contrast medium flowed easily up and down it. Needle biopsy of the right kidney showed normal glomeruli with extensive necrosis of the renal papilla which was included in the specimen. The capillaries in the medulla adjacent to the necrotic area contained fragmented red cells and some capillaries were plugged by these fragments.

The anaemia responded to iron but the urinary infection was not eradicated by nalidixic acid followed by Septrin, although the organism was sensitive to both agents in vitro. Retroperitoneal fibrosis was considered, and at exploration the left ureter was thickened and oedematous from the level of the fourth lumbar vertebra down to the pelvic

Medical Unit, St. Thomas's Hospital, London SE1 7EH

GRAHAM A. MACGREGOR, M.A., M.R.C.P., Lecturer in Medicine N. F. JONES, M.D., F.R.C.P., Consultant Physician and Senior Lecture M. A. BARRACLOUGH, M.R.C.P., Senior Lecturer in Medicine

A. J. WING, D.M., M.R.C.P., Consultant Physician

W. I. CRANSTON, M.D., F.R.C.P., Professor of Medicine brim, but there was no fibrosis of the surrounding retroperitoneal tissues. The ureter was opened and a bougie passed easily up to the renal pelvis and down to the bladder. No papillary fragments or calculi were found. A full thickness biopsy specimen of the ureteric wall was taken which showed some fibrosis of the wall of the ureter and infiltration with chronic inflammatory cells. The epithelium appeared normal. After ureteric drainage by $T$-tube the urine became sterile and the pyrexia settled. I.V.P. in January 1970 showed regression of the hydronephrosis on the left side and both kidneys appeared normal. The blood urea was then $35 \mathrm{mg} / 100 \mathrm{ml}$ and the plasma creatinine $1.4 \mathrm{mg} / 100 \mathrm{ml}$.

On four occasions in the next six months the patient passed some solid tissues in his urine which microscopical examination showed to be necrotic renal papillae. He admitted to taking analgesics from time to time despite advice to the contrary. In August 1970 loin pain recurred on the left and later for the first time on the right side. In October 1970 his renal function was reinvestigated. The urine contained moderate numbers of white cells and $E$. coli was grown on culture. Blood urea was $72 \mathrm{mg} / 100 \mathrm{ml}$, plasma creatinine $3.3-4.2 \mathrm{mg}$ / $100 \mathrm{ml}$. I.V.P. showed hydronephrosis of both kidneys. On the left side excretion of the contrast medium was poor and the ureter could not be seen adequately. On the right side the upper third of the ureter was dilated down to the level of the fourth lumbar vertebra. Beyond this for a distance of $11 \mathrm{~cm}$ the ureter could not be seen but was of normal calibre in the pelvis. Both kidneys now had an irregular outline and had decreased in length, the right by $1.5 \mathrm{~cm}$ and the left by $4 \mathrm{~cm}$. There was noticeable irregularity and clubbing of the calices and loss of cortical substance on both sides. Bilateral ureterograms showed tortuosity and irregularity of the middle third of each ureter with no evidence of intraluminal ureteric obstruction.

In view of the previous histological evidence of ureteritis the patient was treated with prednisone $30 \mathrm{mg}$ a day, the dose being reduced to $5 \mathrm{mg}$ a day after a fortnight. The $E$. coli urinary infection responded to nalidixic acid. After two months of steroid treatment the patient's blood urea remained unchanged at $67-74 \mathrm{mg} / 100 \mathrm{ml}$, the plasma creatinine at $3.4-4.4 \mathrm{mg} / 100 \mathrm{ml}$. Prednisone was withdrawn in January 1971 and the patient was finally persuaded to stop all analgesics.

In October 1971 he had no symptoms. The blood urea was $75 \mathrm{mg} /$ $100 \mathrm{ml}$, plasma creatinine $3 \cdot 1-3.5 \mathrm{mg} / 100 \mathrm{ml}$. The urine contained a trace of albumin and occasional white cells. I.V.P. showed that both kidneys had an irregular outline with considerable loss of renal tissue. The right pelvicaliceal system was normal but some dilatation of the left calices remained. Since then the patient has remained well and his renal function is unchanged.

\section{Case 2}

A 46-year-old paper warehouseman was first seen in January 1970 complaining of malaise and loss of weight. Two months previously he had noticed brown sediment in his urine. He denied taking excessive analgesics. On examination he was anaemic, the blood pressure was $160 / 100 \mathrm{~mm} \mathrm{Hg}$, but no other abnormality was found. Investigations showed: $\mathrm{Hb} 9.0 \mathrm{~g} / 100 \mathrm{ml}$, serum iron $25 \mu \mathrm{g} / 100 \mathrm{ml}$, unsaturated iron binding capacity $515 \mu \mathrm{g} / 100 \mathrm{ml}$, E.S.R. $26 \mathrm{~mm}$ in the first hour, blood urea $66 \mathrm{mg} / 100 \mathrm{ml}$, plasma creatinine $2.9 \mathrm{mg} / 100 \mathrm{ml}$. The urinary sediment contained a few red and white cells but repeated cultures showed no growth. Hippuran renogram showed reduced function of both kidneys with impaired drainage on the right side. I.V.P. showed nothing abnormal in the left urinary tract. The right kidney showed caliceal dilatation and the right ureter was dilated to the level of the pelvic brim and was not seen below this level. Ureterograms showed a normal left ureter but a stricture in the right ureter at the level of the pelvic brim. Contrast medium flowed easily up and down with no evidence of intraluminal obstruction. A needle biopsy specimen of the left kidney showed normal glomeruli; the tubules showed considerable atrophy and there was interstitial fibrosis.

The anaemia responded to oral iron therapy. Over the next year renal function deteriorated without evidence of urinary tract infection. 
Blood urea rose to $120 \mathrm{mg} / 100 \mathrm{ml}$, plasma creatinine to $4.2 \mathrm{mg} / 100 \mathrm{ml}$. His wife at this time expressed concern at the amount of analgesics he was taking and on further questioning he admitted to taking about 15-20 codeine compound tablets a day over the last four years as he had found that they relieved tension at work. He was persuaded to stop taking analgesics. A recent blood urea was $93 \mathrm{mg} / 100 \mathrm{ml}$ and creatinine $3.6 \mathrm{mg} / 100 \mathrm{ml}$. An I.V.P. showed loss of papillary indentations in the calices of both kidneys. The upper right ureter was no more dilated than in January 1970 but the left upper ureter was also slightly dilated.

\section{Case 3}

A 46-year-old housewife was first seen at another hospital in 1964 complaining of bilateral loin pain, worse on the right side. An I.V.P. showed a small right kidney with a narrow cortex and unequal blunting of the calices. The left kidney was normal. There was no evidence of obstruction. Blood urea was normal. A midstream specimen of urine (M.S.U.) grew E. coli. A diagnosis of right-sided chronic pyelonephritis was made and she was treated with various antibiotics over the next four years. In 1964 she was also treated with amitriptyline for depression.

In November 1968 she was admitted with severe left loin pain. I.V.P. showed narrowing of the cortex of both kidneys with blunted calices on both sides, the right more than the left. There was a filling defect in the left middle calix. No growth was found in an M.S.U. at this time. Urea was $30 \mathrm{mg} / 100 \mathrm{ml}$, creatinine clearance was $80 \mathrm{ml} / \mathrm{min}$. Her loin pain abated spontaneously but recurred in August 1969. Investigations then showed no change in the appearances on I.V.P.; blood urea was $51 \mathrm{mg} / 100 \mathrm{ml}$, Hb was $13.0 \mathrm{~g} / 100 \mathrm{ml}$, E.S.R. $42 \mathrm{~mm}$ in the first hour. M.S.U. was sterile. Over the next year she had recurrent pain in the left loin and in September 1970 blood urea had risen to $116 \mathrm{mg} / 100 \mathrm{ml}$. I.V.P. showed a large oval opacity in the left pelviureteric junction and a staghorn calculus in the left kidney. Very little dye was excreted by the right kidney and none at all by the left. Because of the deterioration in renal function it was decided to remove the stones, and her left kidney was explored. Unexpectedly, a thick fibrous sheath was found around the ureter. The ureter was mobilized and freed from this sheath. The left kidney was opened and several large soft stones were removed. Biopsy of the ureter showed periureteric fibrosis. She made an uneventful recovery from this operation and there was no deterioration in the renal function.

In view of the unexpected findings in the left ureter she was transferred to St. Thomas's Hospital for further investigation in October 1970. On clinical examination at this time nothing abnormal was noted. Blood pressure was $120 / 70 \mathrm{~mm} \mathrm{Hg}$. Investigations showed: $\mathrm{Hb} 11.3 \mathrm{~g} / 100 \mathrm{ml}$, E.S.R. $61 \mathrm{~mm}$ in the first hour, urea $90 \mathrm{mg} / 100 \mathrm{ml}$, plasma creatinine $4.7 \mathrm{mg} / 100 \mathrm{ml}$. The urinary deposit was normal, no proteinuria was present, and growth was not found on repeated urine cultures. Hippuran renogram showed impairment of function in both kidneys, worse on the left side. I.V.P. showed thot both kidneys measured $8.5 \mathrm{~cm}$. The right kidney showed dilated and blunted calices with decreased renal substance. The upper one-third of the right ureter was outlined and was normal. The left kidney was not well defined and the ureter was not shown. Ureterograms showed the right ureter to be normal. The left ureterogram showed the ureter to be narrowed and tortuous in a three-inch segment just above the pelvic brim. Contrast medium flowed easily up and down with no evidence of intraluminal obstruction. In view of these findings a diagnosis of retroperitoneal fibrosis involving the left ureter was made, and treatment was started with prednisone $30 \mathrm{mg} /$ day. She was followed in outpatients but after two months there was no improvement in renal function; blond urea was $90 \mathrm{mg} / 100 \mathrm{ml}$, and plasma creatinine $5.1 \mathrm{mg}$ / $100 \mathrm{ml}$. Prednisone was therefore withdrawn.

The patient eventually admitted to having taken large numbers of codeine compound tablets. She said that she had started taking them at the age of 30 because of toothache and found that they made her feel better. Since then she had been consuming about 25 tablets a day and had taken them fairly regularly over the intervening 15 years. She was persuaded to stop her consumption of analgesics, and in the last year she has remained without symptoms, while no further deterioration in renal function has occurred. When last seen in July 1972 the blood urea was $124 \mathrm{mg} / 100 \mathrm{ml}$, creatinine $5 \cdot 1 \mathrm{mg} / 100 \mathrm{ml}$.

It should be noted that none of the patients had been given methysergide. Repeated determinations of plasma electrolytes, plasma calcium, plasma phosphate, plasma urate, plasma protein, and plasma protein electrophoresis on all three cases were within the normal range.

\section{Discussion}

Each of these patients had consumed well over $3 \mathrm{~kg}$ of phenacetin. They all had radiographic changes consistent with analgesic nephropathy, and renal histology in two cases was also compatible with this diagnosis. In all three patients the disease was complicated by dilatation of one or both upper urinary tracts due to ureteric or periureteric fibrosis. None of the patients had been given methysergide.

Ureteric obstruction in analgesic nephropathy may be due to blockage by separated papillae or stones (Hendry et al., 1972), but in these patients there was no evidence of intraluminal obstruction on ureterography and this was confirmed in the two patients who underwent surgical exploration. The findings indicate that they had ureteritis with fibrosis of the ureter and, in one case, of the periureteric tissues. It is noteworthy that the patient in case 1 , who continued to take codeine compound tablets, developed a stricture on the opposite side while the two other cases who stopped analgesics showed no progression of ureteric narrowing and no deterioration in renal function, and we suggest that the ureteritis in these cases is due to analgesic abuse.

In all three patients the lesion appeared to involve the middle third of the ureter down to the pelvic brim. The reason for this is unknown, but it is of interest that the same site is affected by retroperitoneal fibrosis. The ureters were not displaced medially, however, and the fibrosis was much more limited than in retroperitoneal fibrosis, although it is possible that the fibrotic process might have spread had the patients continued to take analgesics. It is, therefore, pertinent to ask whether analgesic abuse might be a cause of retroperitoneal fibrosis. The answer remains uncertain but perusal of the literature reveals a few patients with retroperitoneal fibrosis who gave a history of analgesic consumption (Webb and Dawson-Edwards, 1967). The present cases indicate that any patient with unexplained ureteric stricture or retroperitoneal fibrosis should be questioned closely about analgesic consumption. The difficulty often encountered in eliciting the history from patients who have been abusing analgesics, and the therapeutic opportunity offered by making this diagnosis, underline the importance of awareness of the association which we describe.

\section{References}

Hendry, W. F., Harrison, A. R., and Kilpatrick, F. R. (1972). Proceedings of the Royal Society of Medicine, 65, 1023

Spühler, O., and Zollinger, H. U. (1953). Zeitschrift für klinische Medizin, 151 , 1 .

Webb, A. J., and Dawson-Edwards, P. (1967). British fournal of Surgery,
54,508 . 